\title{
Perancangan Gardu Distribusi Pengembangan Perumahan Green Nurhidayat Romang Polong
}

\author{
Herman Nauwir ${ }^{1 *}$, Muhammad Ruswandi Djalal ${ }^{2}$, Muh. Yusril Hamma' ${ }^{3}$ \\ 1,2,3 Jurusan Teknik Mesin, Politeknik Negeri Ujung Pandang, Makassar 90245, Indonesia \\ *hermannawir@poliupg.ac.id
}

\begin{abstract}
Green Nurhidayat Romang Polong Residence is a new housing located Samata's axis road. In the housing development process, an electrical system is something important to supply electrical power in the housing. The distribution of electricity cannot be separated from the distribution substations. This research was conducted to design distribution substations. This research aims to determine the equipment and determine the capacity of each equipment. This research begins with observation, collects the data and data analysis. Data was collected through document study, observation and interview methods. Based on the results of research, distribution substations on Green Nurhidayat Romang Polong Residence used portal type substation with a transformer with a capacity of $400 \mathrm{kVA}$. The safeguards used are Lightning Arrester has a capacity of $24 \mathrm{kV}, 5 \mathrm{kA}$, Fuse Cut Out with safety capacity of $12.5 \mathrm{~A}$, the conductor area used to connect the Transformer to low voltage panel is a NYY type cable with a cross-sectional area of 4 (1 $x 400$ $\mathrm{mm}^{2}$ ), the conductor on the primary side that connects low voltage grid to Ligtning Arrester and Lightning Arrester to a transformer is AAAC type cable with a cross-sectional area of $35 \mathrm{~mm}^{2}$, while on the low-voltage grid, NFA2X type cable with a cross-sectional area of $3 \times 70 \mathrm{~mm}$ is used. Low voltage panel divided into line, circuit breaker with a safety capacity of $700 \mathrm{~A}$, NH Fuse with a capacity of $224 \mathrm{~A}$ and a rod electrode with a length of $5 \mathrm{~m}$ on the grounding system.
\end{abstract}

Keywords: Distibution System; Design; Distribution Substation

\begin{abstract}
Abstrak: Perumahan Green Nurhidayat Romang Polong merupakan perumahan baru yang terletak di Jalan poros samata. Pada proses pembangunan perumahan sistem kelistrikan merupakan sesuatu yang penting untuk menyuplai daya listrik di perumahan tersebut. Penyaluran listrik pada perumahan ini tidak terlepas dari peranan gardu distribusi. Penelitian ini dilakukan untuk merancang gardu distribusi pada perumahan baru. Penelitian ini bertujuan untuk menentukan peralatan-peralatan distribusi serta menentukan kapasitas tiap-tiap peralatan. Penelitian ini diawali dengan observasi setelah itu melakukan pengumpulan data, lalu dilakukan analisa data yaitu melakukan perancangan gardu distribusi. Pengumpulan data dilakukan melalui metode studi dokumen, metode observasi dan wawancara. Berdasarkan hasil penelitian pada perancangan gardu distribusi peumahan Green Nurhidayat Romang Polong digunakan Gardu tipe portal dengan transformator berkapasitas $400 \mathrm{kVA}$. Pengaman yang digunakan berupa Lightning Arrester, Fuse Cut Out, MCCB dan NH Fuse. Pada Lightning Arrester memiliki kapasitas 24 kV, 5 kA, Fuse Cut Out dengan kapasitas pengaman Fuse Link sebesar 12,5 A, Luas penghantar yang digunakan untuk menghubungkan antara Trafo dengan PHB-TR adalah kabel jenis NYY dengan luas penampang $4\left(1 \times 400 \mathrm{~mm}^{2}\right)$, penghantar pada sisi primer gardu distribusi yang menghubungkan JTR dengan LA serta LA dengan transformator adalah kabel jenis AAAC dengan luas penampang $35 \mathrm{~mm}^{2}$, sementara pada sisi jaringan tegangan rendah digunakan kabel jenis NFA2X dengan luas penampang 3x70 mm. PHB-TR 3 Jurusan, MCCB dengan kapasitas pengaman 700 A, NH Fuse dengan kapasitas 224 A serta elektroda batang dengan panjang $5 \mathrm{~m}$ pada sistem pembumian.
\end{abstract}

Kata kunci: Sistem Distribusi; Perencanaan; Gardu Distribusi

\section{PENDAHULUAN}

Listrik merupakan suatu kebutuhan yang sangat penting bagi manusia. Oleh karena itu, tidaklah berlebihan jika listrik bisa dikatakan sebagai salah satu kebutuhan utama atau pokok bagi penunjang dalam pemenuhan kebutuhan hidup manusia. Terdapat empat bagian penting dalam Sistem Ketenagalistrikan yaitu pembangkit, transmisi, distribusi, saluran distribusi dan pemanfaatan tenaga listrik (beban). Saluran transmisi bertujuan agar mendekatkan jaringan listrik ke pusat-pusat beban setelah itu tenaga listrik tersebut didistribusikan melalui distribusi primer dan sekunder. Pada sistem distribusi dibagi menjadi dua bagian yaitu distribusi primer/jaringan tegangan menengah (JTM) dan distribusi sekunder/jaringan tegangan rendah (JTR). Untuk merencanakan suatu jaringan distribusi primer maupun distribusi sekunder harus memenuhi standar Persyaratan Umum Instalasi Listrik [1]. 
Perumahan Green Nurhidayat Romang Polong merupakan perumahan baru yang terletak di Jalan poros samata kelurahan romang polong. Pada proses pembangunan perumahan ini tidak terlepas dari pembangunan sistem kelistrikan untuk menyuplai daya listrik di perumahan tersebut. Penyaluran listrik pada perumahan ini tidak terlepas dari peranan gardu distribusi. Gardu distribusi berfungsi untuk mentransformasikan tegangan dalam hal ini dari tegangan menengah $20 \mathrm{kV}$ menjadi tegangan rendah 220/380 V. Penelitian ini bertujuan untuk menentukan peralatan-peralatan distribusi serta menentukan kapasitas tiap-tiap peralatan. Penelitian ini diawali dengan observasi setelah itu melakukan pengumpulan data, lalu dilakukan analisa data yaitu melakukan perancangan gardu distribusi. Pengumpulan data dilakukan melalui metode studi dokumen, metode observasi dan wawancara. Oleh karena itu perlu dilakukan perancangan gardu distribusi sesuai standar. Rajak (2017), dengan judul "Perencanaan Gardu Distribusi Dan Jaringan Tegangan Rendah Untuk Melayani Perumahan Greenland Samarinda Jl. M. Said Kelurahan Lok Bahu Sungai Kunjang. Dalam perencanaan gardu distribusi yang dilakukan diketahui beban total perumahan Greenland Samarinda sebesar 228.800 VA maka perencanaan yang distribusi yang dilakukan setelah melalui beberapa perhitungan yaitu dengan menggunakan gardu distribusi tipe portal dengan transformator dengan kapasitas $250 \mathrm{kVA}$ yang dibagi menjadi 3 jurusan. Pengaman yang digunakan berupa lightning arrester, fuse cut out, MCCB dan fuse cartridge. Pada lightning arrester memiliki kapasitas $24 \mathrm{kV}, 10 \mathrm{kA}$, fuse cut out dengan kapasitas pengaman fuse link sebesar 8 Ampere, MCCB dengan kapasitas pengaman 300 A dan fuse cartridge dengan kapasitas 160 Ampere pada jurusan 1, 2 dan 3. Luas penghantar yang digunakan untuk menghubungkan antara trafo dengan PHB TR adalah Kabel jenis NYY dengan luas penampang 4 x $300 \mathrm{~mm}^{2}$. Untuk kabel penghubung keluaran dari PHB-TR ke jaringan tegangan rendah menggunakan penghantar jenis NYY dengan luas penampang $4 \times 70 \mathrm{~mm}^{2}[2]$.

\section{METODE PENELITIAN}

Penelitian ini diawali dengan observasi setelah itu melakukan pengumpulan data, lalu dilakukan analisa data yaitu melakukan perancangan gardu distribusi. Pengumpulan data dilakukan melalui metode studi dokumen, metode observasi dan wawancara. Penelitian ini dilaksanakan di Perumahan Green Nurhidayat Romang Polong JL. Poros Samata Kel Romang Polong Kab. Gowa penelitian dan pengambilan data mulai pada bulan Juli 2021. Adapun rumus-rumus yang digunakan dalam menghitung kapasitas peralatan pada gardu distribusi antara lain:

a. Penentuan kapasitas Fuse link

$$
\frac{S}{\sqrt{3} x V_{L-L}}
$$

b. Penentuan arus nominal

$$
\text { In }=\frac{s}{V}
$$

c. Penentuan KHA penghantar

$$
\mathrm{KHA}=\operatorname{In} \times 125 \%
$$

d. Penentuan resistansi tanah

$$
R=\frac{\rho}{2 \pi L}\left\{\ln \frac{4 L}{a}-1\right\}
$$

\section{HASIL DAN PEMBAHASAN}

a. Perumahan Green Nurhidayat Romang Polong

Perumahan Green Nurhidayat Romang Polong adalah perumahan yang terletak di RomangPolong, Kecamatan Somba Opu, Kabupaten Gowa, Sulawesi Selatan. Perumahan ini terdiri dari 370 unit rumah yang akan memerlukan suplai listrik. 
239 Herman Nauwir, Muhammad Ruswandi Djalal, Muh. Yusril Hamma. Perancangan Gardu Distribusi Pengembangan Perumahan Green Nurhidayat Romang Polong

\section{b. Perkiraan Beban Tersambung}

Pada perancangan gardu distribusi perumahaan Nurhidayat Romang Polong kali ini diketahui jumlah rumah yang akan disuplai listrik ialah 370 unit. Pemakaian daya pada masing-masing rumah terbagi menjadi 3 jenis, yaitu: rumah type $70=3.500 \mathrm{VA}(16 \mathrm{~A})$ dengan jumlah 50 unit, rumah type $45=2.200 \mathrm{VA}(10 \mathrm{~A})$ dengan jumlah 120 unit, dan rumah type $36=1.300 \mathrm{VA}(6 \mathrm{~A})$ dengan jumlah 200 unit. Dengan jumlah beban tersebut maka gardu distribusi ada perancangan kali ini dibagi menjadi 3 jurusan. Berdasarkan tabel 2.1 karena perumahan Green Nurhidayat Romang Polong termasuk dalam kategori daerah perumahan sedang/campuran rumah biasa dengan jumlah rumah sebanyak 370 unit, maka faktor koreksi pada perencanaan gardu distribusi perumahan Green Nurhidayat Romang Polong adalah sebesar 0,4 [3].

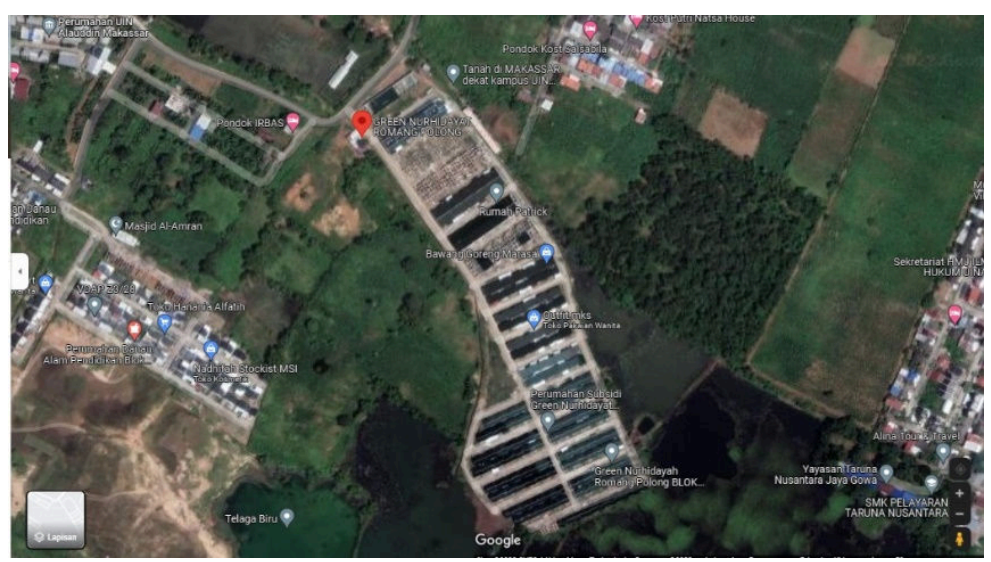

Gambar 1 Penampakan Perumahan Green Nurhidayat Romang Polong dari satelit

\section{c. Pembagian Beban}

Pembagian beban pada perumahan Green Nurhidayat Romang Polong terbagi menjadi 3 jurusan. Masing-masing jurusan terdiri dari 3 type rumah dengan daya yang telah ditentukan (3.500 VA, $2.200 \mathrm{VA}$, dan $1.300 \mathrm{VA}) ; 123$ unit rumah pada jurusan 1,123 unit rumah pada jurusan 2 , dan 124 unit rumah pada jurusan 3. Berikut merupakan hasil perhitungan pembagian beban pada perumahan Green Nurhidayat Romang Polong berdasarkan daya.

Tabel 1 Pembagian Beban

\begin{tabular}{|c|c|c|c|c|c|c|c|}
\hline \multirow[b]{2}{*}{ Jurusan } & \multicolumn{3}{|c|}{ Jumlah beban (unit) } & \multicolumn{3}{|c|}{ Daya } & \multirow[b]{2}{*}{ Total } \\
\hline & $\begin{array}{c}\mathrm{R} \\
(3.500 \\
\mathrm{VA})\end{array}$ & $\begin{array}{c}\text { S } \\
(2.200 \\
\text { VA) }\end{array}$ & $\begin{array}{c}\mathrm{T} \\
(1.300 \\
\mathrm{VA})\end{array}$ & $\mathrm{R}$ & $\mathrm{S}$ & $\mathrm{T}$ & \\
\hline 1 & 16 & 42 & 65 & 56.000 & 92.400 & 84.500 & 232.900 \\
\hline 2 & 17 & 40 & 66 & 59.500 & 88.000 & 85.800 & 233.300 \\
\hline 3 & 17 & 38 & 69 & 59.500 & 83.600 & 89.700 & 232.800 \\
\hline
\end{tabular}

d. Perhitungan Beban Puncak

Berdasarkan uraian pada poin 4.2 diatas, daya yang diperlukan pada perumahaan Green Nurhidayat Romang Polong adalah:

1. Rumah Type $70=50 \times 3.500 \mathrm{VA}=175.000 \mathrm{VA}$

2. Rumah Type $45=120 \times 2.200 \mathrm{VA}=264.000 \mathrm{VA}$

3. Rumah Type $36=200 \times 1.300 \mathrm{VA}=\underline{260.000 \mathrm{VA}+}$

Total daya $\quad=699.000 \mathrm{VA}$ 
Untuk mengetahui nlai beban puncak, hasil dari perhitungan total daya di atas dikali dengan faktor koreksi berdasarkan tabel 2.1 sebesar 0,4 (Heru, 2006) sehingga:

$699.000 \times 0,4=279.000 \mathrm{VA}$

Berdasarkan perhitungan beban puncak di atas, diketahui bahwa penggunaan transformator dengan pembebanan $80 \%$ dari total kapastas transformator ialah $279.000 \mathrm{VA}$.

e. Kapasitas Peralatan Gardu Distribusi

1. Transformator Distribusi

Berdasarkan perhitungan beban puncak pada poin 4.4, untuk menghindari terjadinya overload dan penambahan beban dikemudian hari, maka untuk mengetahui kapasitas transformator distribusi yang digunakan, terlebih dahulu perlu diketahui penggunaan transformator dengan beban penuh (100\%) maka:

$$
\frac{279.000}{0,8}=348.750 \mathrm{VA}
$$

Berdasarkan hasil perhitungan diatas, maka kapasitas transformator distribusi yang digunakan adalah $400 \mathrm{kVA}$.

\section{LA (Lightning Arrester)}

Lightning Arrester adalah pengaman transformator dari sambaran petir, Untuk menentukan jenis arrester yang akan di gunakan pada tegangan sistem $20 \mathrm{kV}$, maka: $110 \%$ × $20.000 \mathrm{~V}=$ $22.000 \mathrm{~V}$. Jadi, berdasarkan perhitungan digunakan arrester dengan tegangan nominal $24 \mathrm{kV}$ dan arus $5 \mathrm{kA}$, karena gardu distribusi berada di tengah jaringan [4].

3. FCO (Fuse Cut Out)

Untuk mengamankan transformator yang berkapasitas $400 \mathrm{kVA}$ dari gangguan hubung singkat dan sebagai pembatas bila terjadi beban lebih (overload) pada transformator menggunakan fuse cut out. Menentukan rating arus fuse link yang akan digunakan pada tabung fuse cut out terlebih dahulu menentukan arus nominal dari transformator berkapasitas $400 \mathrm{kVA}$ dengan tegangan kerja $20 \mathrm{kV}$ dapat ditentukan arus yang mengalir dengan menggunakan persamaan.

$$
\begin{aligned}
& \frac{S}{\sqrt{3} \times V_{L-L}} \\
& \frac{400.000 \mathrm{VA}}{\sqrt{3} \times 20.000 \mathrm{~V}} \\
& =11,55 \mathrm{~A}
\end{aligned}
$$

Berdasarkan tabel 2.2 besar pengaman fuse link yang digunakan adalah sebesar 12,5 A pada transformator berkapasitas $400 \mathrm{kVA}$

\section{Kabel Penghantar}

Dalam menentukan luas penampang kabel yang digunakan, hal pertama yang harus diketahui adalah nilai In yang dapat ditentu]'kan dengan menggunakan persamaan

$$
\begin{aligned}
& \text { In }=\frac{S}{\sqrt{3} \times V_{L-L}} \\
& \text { In }=\frac{400.000 \mathrm{VA}}{\sqrt{3} \times 380 \mathrm{~V}} \\
& \mathrm{In}=607,74 \mathrm{~A}
\end{aligned}
$$

Setelah mendapatkan nilai arus nominal untuk menentukan nilai kapasitas hantar arus dengan menggunakan persamaan

$$
\begin{aligned}
\mathrm{KHA} & =\operatorname{In} \times 125 \% \\
& =607,74 \mathrm{~A} \times 1,25 \\
\mathrm{KHA} & =759,67 \mathrm{~A}
\end{aligned}
$$

Dengan demikian jenis penghantar yang digunakan adalah jenis kabel NYY. Berdasarkan 
241 Herman Nauwir, Muhammad Ruswandi Djalal, Muh. Yusril Hamma. Perancangan Gardu Distribusi Pengembangan Perumahan Green Nurhidayat Romang Polong

Hasil perhitungan KHA yang dihasilkan adalah 759,67 A, maka dapat dilihat pada tabel 2.6 luas penampang yang digunakan adalah luas penampang dengan ukuran $400 \mathrm{~mm}^{2}$, serta konstruksi kabel yang digunakan adalah NYY $4\left(1 \mathrm{x} 400 \mathrm{~mm}^{2}\right)$.

Untuk penghantar pada jaringan tegangan menengah yang terhubung pada sisi primer gardu distribusi yaitu LA dan FCO dapat ditentukan menggunakan persamaan

$$
\begin{aligned}
& \frac{S}{\sqrt{3} \times V_{L-L}} \\
& \frac{400.000 \mathrm{VA}}{\sqrt{3} \times 20.000 \mathrm{~V}} \\
& =11,55 \mathrm{~A}
\end{aligned}
$$

Berdasarkan hasil perhitungan, arus yang mengalir ialah 11,55 A dengan demikian berdasarkan tabel 2.7 konstruksi kabel yang digunakan yaitu AAAC dengan luas penampang $16 \mathrm{~mm}^{2}$.

Pada sistem jaringan tegangan rendah untuk melayani tiap rumah digunakan kabel LVTC dengan jenis NFA2X dengan luas penampang $3 \times 70 \mathrm{~mm}$. Adapun nilai resistansi pada jenis kabel tersebut adalah $0,443 \mathrm{Ohm} / \mathrm{Km}$.

5. MCCB (Moulded Case Circuit Breaker)

Dalam menentukan pengaman utama yang digunakan, dapat menggunakan persamaan:

$$
\begin{aligned}
& \text { In }=\frac{S}{\sqrt{3} \times V_{L-L}} \\
& \text { In }=\frac{400.000 \mathrm{VA}}{\sqrt{3} \times 380 \mathrm{~V}} \\
& \text { In }=607,74 \mathrm{~A}
\end{aligned}
$$

Berdasarkan tabel 2.4 maka pengaman yang digunakan adalah pengaman yang mempunyai rating arus yaitu sebesar $700 \mathrm{~A}$, karena dipilih yang terdekat dari 607,74 A.

6. NH Fuse

Dalam menentukan rating NH Fuse yang digunakan, hal pertama yang harus diketahui adalah nilai In yang dapat ditentukan dengan menggunakan persamaan

$$
\begin{aligned}
& \text { In }=\frac{S}{\sqrt{3} \times V_{L-L}} \\
& \mathrm{In}=\frac{400.000 \mathrm{VA}}{\sqrt{3} \times 380 \mathrm{~V}} \\
& \mathrm{In}=607,74 \mathrm{~A}
\end{aligned}
$$

Dari hasil perhitungan di atas maka kapasitas NH Fuse utama yang digunakan ialah 630 A. Untuk menghitung kapasitas $N H$ Fuse tiap jurusan maka perlu diketahui jumlah jurusan yang disuplai oleh gardu distribusi. Pada Gardu Distribusi perumahan Green Nurhidayat Romang Polong dibagi menjadi 3 jurusan, maka:

$$
\begin{aligned}
& =\frac{607,74}{3} \\
& =202 \mathrm{~A}
\end{aligned}
$$

Berdasarkan tabel 2.5 maka pengaman yang digunakan adalah pengaman yang mempunyai rating arus sebesar $224 \mathrm{~A}$.

\section{f. Pembumian Gardu Distribusi}

Pada perencanaan gardu distribusi perumahan Green Nurhidayat Romang Polong, gardu distribusi dipancang pada jenis tanah liat dan tanah ladang dan berdasarkan tabel 2.9 nilai tahanan jenis pada jenis tanah tersebut sebesar $100 \Omega \mathrm{m}$. Maka untuk menentukan nilai tahanan pembumian dapat ditentukan dengan persamaan

$$
\begin{array}{cl}
\text { Diketahui: } \quad & \rho=100 \Omega \mathrm{m}=1000 \Omega \mathrm{cm} \\
\mathrm{L}=5 \mathrm{~m}=500 \mathrm{~cm} \\
\mathrm{a}=5 / 8 \mathrm{inch}=1,58 \mathrm{~cm} \div 2=0,79 \mathrm{~cm} \\
\mathrm{R}=\frac{\rho}{2 \pi L}\left\{\ln \frac{4 L}{a}-1\right\}
\end{array}
$$


$\mathrm{R}=\frac{1000}{2.3,14.500}\left\{\ln \frac{4.500}{0,79}-1\right\}$

$\mathrm{R}=\frac{1000}{3140}\left\{\ln \frac{2000}{0,79}-1\right\}$

$\mathrm{R}=0,31(\ln 2531,64-1)$

$\mathrm{R}=0,31(7,8-1)$

$\mathrm{R}=0,31(6,8)$

$\mathrm{R}=2,10 \Omega$

Maka untuk perencanaan kali ini digunakan elektroda pembumian jenis elektroda batang dengan panjang 5 meter sejumlah 3 batang yang dipasang secara paralel. Penghantar-penghantar pembumian dilindungi dengan tembaga dengan diameter 5/8 inci sekurang-kurangnya setinggi 3 meter diatas tanah.

g. Tiang Penyangga

Pada perancangan gardu distribusi Perumahan Green Nurhidayat Romang Polong, tiang penyangga yang digunakan ialah jenis tiang beton dengan panjang 11 meter yang ditanam dengan kedalaman $\frac{1}{6}$ dari panjang tiang.

h. Gardu Distribusi Perumahan Green Nurhidayat Romang Polong

Gardu distribusi yang akan dirancang adalah gardu tipe portal pasangan luar
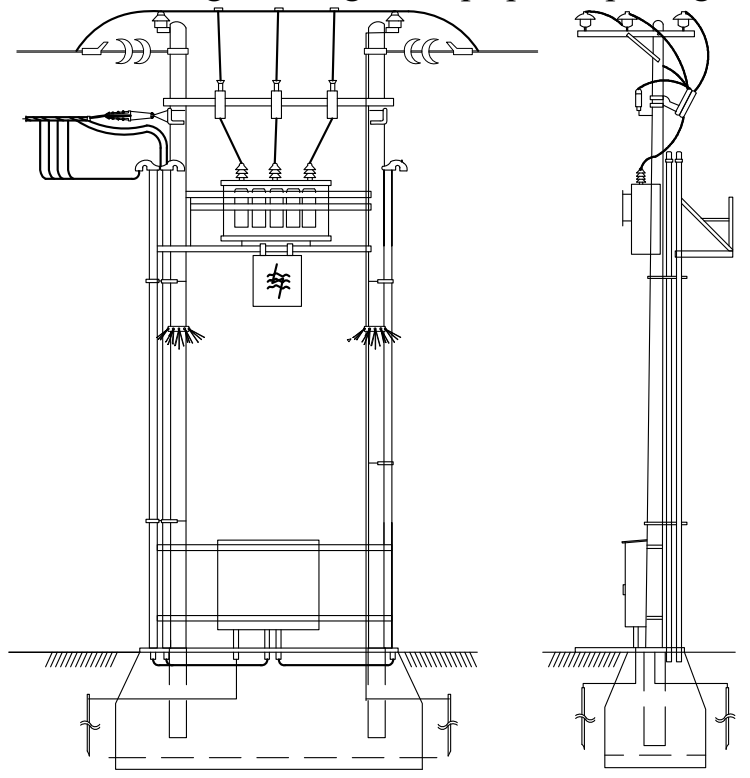

Gambar 2 Penampakan Gardu Distribusi

\section{KESIMPULAN}

Berdasarkan pembahasan pada penelitian ini maka diperoleh kesimpulan sebagai berikut :

1. Peralatan-peralatan yang digunakan pada sebuah perancangan Gardu Distribusi antara lain), LA (Lightning Arrester), FCO (Fuse Cut Out), Kabel Penghantar, Transformator Distribusi, Perlengkapan Hubung Bagi Tegangan Rendah (PHB-TR), MCCB (Moulded Case Circuit Breaker), NH Fuse dan Elektroda Pembumian.

2. Pada perancangan gardu distribusi peumahan Green Nurhidayat Romang Polong digunakan Gardu tipe portal dengan transformator berkapasitas $400 \mathrm{kVA}$. Pengaman yang digunakan berupa Lightning Arrester, Fuse Cut Out, MCCB dan NH Fuse. Pada Lightning Arrester memiliki kapasitas 24 kV, 5 kA, Fuse Cut Out dengan kapasitas pengaman Fuse Link sebesar 12,5 A, Luas penghantar yang digunakan untuk menghubungkan antara Trafo dengan PHB-TR adalah kabel jenis NYY dengan luas penampang $4\left(1 \mathrm{x} 400 \mathrm{~mm}^{2}\right)$, penghantar pada sisi primer gardu distribusi yang 
243 Herman Nauwir, Muhammad Ruswandi Djalal, Muh. Yusril Hamma. Perancangan Gardu Distribusi Pengembangan Perumahan Green Nurhidayat Romang Polong

menghubungkan JTR dengan LA serta LA dengan transformator adalah kabel jenis AAAC dengan luas penampang $35 \mathrm{~mm}^{2}$, sementara pada sisi jaringan tegangan rendah digunakan kabel jenis NFA2X dengan luas penampang 3x70 mm. PHB-TR 3 Jurusan, MCCB dengan kapasitas pengaman $700 \mathrm{~A}, \mathrm{NH}$ Fuse dengan kapasitas 224 A serta elektroda batang dengan panjang $5 \mathrm{~m}$ pada sistem pembumian.

\section{DAFTAR PUSTAKA}

[1] Suryatmo, "Teknik listrik instalasi penerangan, PT. Rineka Cipta”, Jakarta, 2004.

[2] Abdul Rajak. Perencanaan Gardu Distribusi Dan Jaringan Tegangan Rendah Untuk Melayani Perumahan Greenland Samarinda J1. M. Said Kelurahan Lok Baru Sungai Kunjang. Tugas Akhir. Samarinda: Politeknik Negeri Samarinda. 2017.

[3] Heru Subagy. Kondisi Ketenaga Listrikan di Indonesia dan Upaya Mewujudkan Ketenaga Listrikan yang Andal, Aman dan Akrab Lingkungan. Jakarta: APEI. 2006

[4] PT. PLN (Persero). Buku 4 Standar Kontruksi Gardu Distribusi dan Gardu Hubung Tenaga Listrik. Jakarta Selatan : PT. PLN (Persero). 2010. 